KIM D. CUPIDO \& JEAN-PAUL VAN BELLE

\title{
A DIGITALLY ENABLED STRATEGIC SOURCING PROCESS TO MITIGATE RISK ${ }^{1}$
}

\begin{abstract}
ABC Insurance was a leading short-term insurer in South Africa. The FSB (Financial Services Board) of South Africa defined short term insurance cover as indemnification secured by the insurance purchaser over their fixed and movable assets (FSB, n.d.). Such insurable assets could be one's home (the actual building) or motor vehicle (https://www.fsb.co.za). The purchased insurance cover protected the policyholder (customer) against total loss or accidental damage, as a result of insurable events like fires or floods. In exchange, payment for insurance cover (referred to as the "premium"), was collected by the insurance company from its customers. Andrew Cohen, commodity manager for the Non-Automobile Property and Casualty procurement division at ABC Insurance, was faced with the choice of either digitizing the day to day claims fulfillment procedures within his portfolio, or to continue his business unit's activities "as is."
\end{abstract}

The main function of Cohen's business unit was to ensure that home owners (policyholders) who purchased insurance cover over their fixed assets (i.e., buildings insurance) could access and receive the required repair services as per the provisions set out in their insurance policies. In delivering these services to the policyholders, Cohen's immediate challenges were that he had to increase efficiency within the claims environment, meet customer demand and enhance operational processes while concurrently accelerating daily business operations. In opposition to maintaining the status quo, his options were to either build an in-house solution, or purchase an existing tool and customize it to his organization's requirements. His preliminary cost benefit analysis showed that choosing to remain "as is" would cost the firm nothing in terms of immediate cash outflows, but in the long term would expose management to the risk of not capitalizing on opportunities to service their customers quickly and efficiently, infuse transparency into the appointment procedure of suppliers on repair claims, and gain line of sight of interactions between the firm, its service providers, and its customers. He furthermore surmised that whatever the solution was it might require the firm to make initial investments of time for the re-organization of internal processes and new information technology competencies to acquire. To select an ideal solution, he would need to weigh the risks of remaining "as is" against the benefits of infusing mobile technology such as a mobile app into his portfolio, and ultimately, into the core day-today operations of the firm as well.

\footnotetext{
${ }^{1}$ Copyright (C) 2017, Kim Cupido \& Jean-Paul Van Belle. This case was prepared for the purpose of class discussion, and not to illustrate the effective or ineffective handling of an administrative situation. Names and some information have been disguised. This case is published under a Creative Commons BY-NC license. Permission is granted to copy and distribute this case for non-commercial purposes, in both printed and electronic formats.
} 


\section{The South African Marketplace}

According to the Insurance Institute of South Africa, South Africa was home to the largest insurance market on the African continent ("Opportunity for Insurers," 2015). Its economy was distinctive in that it incorporated a mix of first world capability with proficiencies typically found to be true of developing markets. The United Nation's definition of a developing economy describes such countries as having a relatively low standard of living, an underdeveloped industrial base comprising of low value add sectors such as agriculture and natural resource extraction, and a medium Human Development Index standing at 0.666 in 2014 (UN Human Development Report, 2015). In order to understand how South Africa came to be a mixed economy, it was relevant to explore its past in order to identify potential opportunities in Cohen's future solution.

\section{When the Past Informs the Future}

Apartheid, an institutionalized system of race-based segregation and discrimination, left its impact on South Africa economically, socially, commercially, and technologically (Wikipedia, 2016). This legislated system of segregation was enforced by the ruling party from 1948 to 1991. It permeated the social structures in terms of legal and political rights, the living standards, and the business opportunities of non-white South Africans. Interracial contact was taboo, and education, neighborhoods, and business activities were strictly divided by ethnicity, gender, language, and creed. Post the 1994 universal franchise elections, not only did management at ABC Insurance have to resolve the disputes between its customers and suppliers, but the distinctive South African business environment meant that managers actively had to build relationships across social barriers, the economic divide, ethnic bias, and racial stereotyping. Much harder for management to combat was the legacy apartheid left in terms of policyholder perceptions of the persons performing the repair work at their residences which ultimately informed the frequency of complaints, and the frequency of re-work insurers had to deal with. Adding to this pressure was the actuality of a limited pool of available prospective customers for which insurers had to compete fiercely to secure premium income.

\section{ICT Sector}

The positive effect of South Africa's mixed economy was largely felt in its information technology and communications sectors. Owing to the widespread availability mobile devices and consumers preferred consumption of data, Cohen realized the possibilities that stood before him. The digital divide that existed in South Africa over the last 15 years had narrowed rapidly over a relatively short period of time. According to Statistics South Africa (2012), the percentage of households who owned cellular phones increased from 32\% in 2001, to $89 \%$ in 2011. Proportionately over the same period, the percentage of households who owned computers only grew from $8.5 \%$ to $21 \%$. Census data furthermore revealed that mobile devices [cellular phones] were predominantly used to access the internet. Subsequently, the adoption rate of mobile 3G and Long-Term Evolution (LTE) technologies far surpassed alternate choices such as fixed broadband and asymmetric digital subscriber line (ADSL) options, not only because of individual consumer cost factors, but also because of mobile versus fixed line throughput speeds (South African Journal of Information, 16(1)). In post-democratic South Africa, the insurance landscape changed drastically from the patriarchal middle aged caucasian male who was traditionally the head of the household and sole breadwinner that made all financial decisions on behalf of the family. Insurers now faced a new reality where purchasing decisions were being made by persons of both genders, who were younger, digitally enabled, and extremely tech savvy.

\section{Economic Challenges}

While South Africa did enjoy a progressive ICTS framework, its statutory deficits stalled an elevation in standards of living and long term sustainable economic growth. To its detriment, three overarching factors 
plagued the South African marketplace: its hindered GDP performance as a result of high unemployment rates and recent political uncertainty, its frail legislative policies, and its inconsistent regulatory practices (Gillwald, Moyo, \& Stork, 2012). In 2016, the South African government, via private sector initiatives, resolved to support small and medium enterprises and strengthen entrepreneurship within its borders. The impetus in contributing to stimulating growth within the economy was therefore an important focal point not only to avoid investment ratings downgrades, but also for ABC Insurance which venerated its contributions to socio-economic investment initiatives. Furthermore, the convergence of unemployment and lagging GDP affected insurance companies in a unique way, as elevated unemployment levels meant the pool of available customers with insurable assets was significantly smaller. What this meant, in effect, was that sources of premium income [customers] were limited, and that each rand of premium income collected had to stretch farther. Subsequently, insurers experienced higher and more frequent claims ratios due to burglary and theft. Considering that contemporary thought leadership revealed that insurance was largely regarded as a "grudge purchase," instances of insurance related fraud were an ever present threat. Job creation and the stimulus of the economy were therefore of prominent concern to big business throughout the country ("Insurance," 2008). Moreover, this new technological capability also allowed previously disadvantaged business owners and entrepreneurs to vie for opportunities in the mainstream economy. Cohen realized this convergence of insurance risk, IT capability, and need for economic growth created the ideal opportunity for an innovative solution to an existing challenge in the environment.

\section{The Company}

In January 2015, the new CEO of ABC Insurance declared that no new staffing resources would be acquired, savings targets would be increased by $10 \%$, and that only well-defined strategic projects would be signed off in the new 2017 budget cycle. In short, the message from the top was for managers to mine the tools they already had to derive maximum benefit for the firm. Cohen was part of an achievement driven management team which despite strained economic times, paid out in excess of R14 billion in claims, declared a return on capital of 32.5\%, and disbursed to its shareholders final dividends of 528 cents per share. At the end of the 2015, the non-automobile property and casualty unit accounted for $49 \%$ of the total claims spend equaling almost R150 million rand. Cohen knew the optimal solution to this challenge was to bring onboard a technology, since previous deployment of technology enablers within the businesses operating units had resulted in gross savings of R195 million over a 3 year period, 26\% reduction operational expenses, and net savings in fees for external operational support funding. Exhibit 1 outlines the critical procurement areas he had to re-engineer in order for his division to become a more valuable strategic business enabler for the firm.

The enterprise's executive team, in its 2016 strategic planning, demarcated four main focus areas for its short to medium term ( $1-3$ years) forecast. They wanted to grow the firm's market share, better manage underwriting risk, increase operational efficiency, and increase its top line revenue by $15 \%$. Towards the end of 2016, the CEO also recommitted the company's resolve to growing and developing SME's. ABC insurance was among the first of the major firms to come onboard with the initiative to support this vital component in the mix of South Africa's economy, in order to foster a more prosperous and better South Africa. Senior managers were faced with the challenge of resolving continuous disputes between its policyholders [customers] and its suppliers [vendors]. The relationship between the two groups was tenuous at best and completely non-functional at worst. Added to this dilemma, were the operational inefficiencies within the enterprise in terms of its processes, outdated policies, and the existing disconnect amid business units within the various functional areas. In response, ABC Insurance then undertook to transform itself into an organization that fostered a culture of inclusiveness that transcended ethnic, 
economic, and gender barriers. Cohen's mission was therefore threefold: service the client, support the small business owner, and support businesses strategic intent.

Another major challenge for South African corporates after democracy was how to assess, measure and quantify the new landscape. A segmentation tool, the Living Standards Measure (LSM), was conceived as a result by the South African Audience Research Foundation (1993) to group the market across variables such as race, gender, and age in categories from 1 to 10. After apartheid, the balance of power between sellers and buyers shifted to the buyers (or customers) who were now able to demand services such as being serviced in the language of their choice [South Africa has 11 official languages], and by persons who were representative of themselves. Through Broad Based Black Economic Empowerment (BBBEE) initiatives were introduced to redress the inequalities of the past, and the South African Department of Trade and Industry aimed to boost wealth generation ability and much needed employment prospects for previously disadvantaged groups (South African Department of Trade and Industry, n.d.). Cohen therefore also had to solve the problem of ensuring the quality of BBBEE repair suppliers on the firm's service provider panel. Personal safety concerns of customers needed to be considered as insurance repairs would require suppliers to perform the repairs at the policyholder's private residence. Within corporate South Africa, Employment Equity (EE) initiatives were endorsed to economically uplift employees. These EE initiatives were largely responsible for the creation of South Africa's Black middle class, known as "Black Diamonds" (Wikipedia, 2016). The exponential increase in the numbers of upwardly mobile "Black Diamonds" and the resultant voracious consumption of goods and services created a new market segment whose needs and preferences short term insurers had never considered before. ABC Insurance therefore embarked on a journey of transformation [within its own structures] to create value for its stakeholders by embracing this new marketplace.

\section{IT Strategy}

Historically, insurance companies reaped substantial benefits from advances in technology (KPMG, n.d.). Based on its business model to target higher level LSM groups who had the requisite disposable income to pay a premium for first-class insurance services, ABC's desired customer was now the very same upwardly mobile high-income earners found to be enthusiastic early adopters of leading edge technologies. The use of digital technologies had only become of strategic importance within the firm over the previous 24 months. Since the latter part of 2015, ABC Insurance had increased its strategic focus on digital projects to leverage opportunities that delivered positive impact upon the business. One of its identified top priorities for the foreseeable future was offering insurance services via a digital platform. It planned to deliver such services over the following two years.

Unfortunately, in the digital area, ABC Insurance needed to catch up with some of its competitors. Newer insurers in the marketplace charted an entirely different service delivery model by cutting out the middleman and providing direct insurance to its customers. This effectively meant they were delivering short term insurance services faster and cheaper. ABC Insurance had in 2010 altered its product profile to provide direct insurance to the market, but found its competitors were ahead of the pack in their execution and delivery of the model to the market. Over time, and with its mixed insurance model, the need for a digital roadmap for ABC Insurance became increasingly evident. Among its most recent IT acquisitions were predictive analytics, business intelligence, and geospatial analytical tools in the claims operations and underwriting environments. Cohen surmised that the existing hardware and software infrastructures were adequate enough to meet the requirements for integration and acquisition of a mobile digital solution. Given the existing operational data volumes, he deduced that the solution required would need to be scalable, and anticipated that data volumes would increase relatively slowly at first, then potentially exponentially over time as more opportunities for Business Intelligence (BI) and analytics insights were identified by users and managers. 


\section{Architecture and Infrastructure}

Within its IT area, Cohen identified many potential areas for improvement. A mix of legacy technologies (claims communications system), standalone systems in the claims processing area, and isolated platforms in the claims handling area resulted in disjointed customer interactions, delayed claims progress tracking, and an inefficient flow of claims related information between the business units. The causes thereof, Cohen established, were workflows and duplicated applications used in isolation by individual business units, that all interfaced with an archaic mainframe system. The main gap in the existing claims processing lifecycle was that claims registration procedures were too manual and too admin intensive. The knock-on effects of these system fissures were felt within the organization and externally on both the client-side and supplier-side.

On the client side, the policyholder system, which for procurement purposes held the specifications in terms of volume, type, and location of specific repair skills required at any given point in time, was completely separate from the unit, and the output from the system was unstructured and cumbersome to transform into usable knowledge or data points. While some of its solutions were cloud based, certain data warehouse systems and data storage locations decisions were made using company policy as a guideline in order to mitigate enterprise risk. The firm had however gone some way to acquire newer business intelligence (BI) technologies such QlikView and geospatial software on which policyholder, supplier, and weather data could be factored and compared for current and future initiatives. Some technologies however, and certain payment systems, were strategically configured as standalone systems. Throughout the claims handling process the customer would receive excessive numbers of SMS (Short Message Service) and email notifications regarding the registration of the claim, their claim number, their appointed claims handler, and the appointment of a supplier. These communications fundamentally excluded pertinent information regarding supplier/service provider identification, supplier timelines for attending to the claim, or when the client could reasonably anticipate contact from the supplier. Claims registrations staff members would then notify the client via telephone during the same time period as the SMS campaign was being executed.

As the customer was bombarded with constant communication about service resolution which created a heightened expectation of efficient servicing, the supplier of the repair service was not aware of the policyholder expectations created by these claims related communications. The supplier was fated to failure even before the repair job had begun. Added to that, South Africa's volatile weather patterns typically produced 4 to 8 instances per year where "catastrophe” repair response by insurance providers was required. The overarching result was that, after repairs had been carried out, the customer was left feeling over promised and under-delivered. With the introduction of a mobile app into the procurement operational space, ABC insurance would be able to bridge the gap between their clients [the policyholders], itself [the procurement unit], and the appointed Property and Casualty service providers.

In setting his priorities, Cohen felt that he would first need to manage the inefficiency within operations in terms of the unit's communications practices, the systems on which those communications occurred, and the unrealistic expectation created with the customer, and subsequent unfair treatment of his suppliers (see Exhibit 3). He also realized that the aforementioned supplier was an integral part of the firm's customer service value chain, and its larger customer relationship management (CRM) process. The communications Cohen observed also did not accommodate for the subsequent procurement involvement which kicked off upon the assessor's approval of repairs to be undertaken. To address these issues, in the preceding 24 months, the various claims divisions were reorganized so as to centralize functions into one physical and virtual location in order to improve efficiency. 
During the same time frame the enterprise had also begun to bring the various standalone technology platforms together into the mainstream business. The business was essentially run on a JD Edwards mainframe with various standalone systems which supported specific business units that backed up to the mainframe once or twice in a 12 or 24-hour cycle using either batched TCP/IP or single process FTP protocols. The integration between the mainframe and the stand-alone systems was not seamless due to the mix of old and new technologies. This lack of full integration led to a complex administration, heavy additional manual processing, and some isolated business decisions. While the net effect of these consolidation efforts on the business was marginal, he foresaw that they would ultimately enable a more sophisticated technology that could be deployed freely across the country, and could double or possibly triple the benefit of their unification efforts. Additionally, a web enabled interface would provide a bridge between the claims administration system and the claims payment system that was ostensibly run on an earlier version of Oracle.

\section{Re-engineering the Procurement Processes}

Underpinning the motivation for change, Theo Mortensen, Manager of the firm's claims philosophy, policy and technical advice unit, summed up the organization's CRM challenges by stating: "If the customer received poor customer service, he/she will not be willing to engage further with us. However, if the [customer] service was excellent... the customer will engage with us further.” Barry Brown, Senior Manager for Procurement supported Mortensen's sentiment by constantly encouraging his staff members to: "Get the right suppliers, to the right jobs, at the right time, and at the right cost."

In order to advance the above procurement methodologies, Cohen's "to be” strategy would need to be applied in light of the following context. Procurement needed to consider:

1. What was our procurement value proposition?

2. What was the landscape of the procurement environment?

3. What defined strategic sourcing?

4. How would we navigating the path from our current state to our desired future state?

Cohen found that the unit's value proposition related acutely to the overall company strategy, and had up until then, never been considered in light of the internal customers which it serviced. In focusing so intently on supporting the company objectives, the non-automobile property and casualty portfolio had completely lost sight of their most important asset: the supplier. All their efforts up until then had resulted in a hostile, wild-west type situation where procurement felt distant from its asset, and claims operations did what they wanted, often counter intuitively costing additional time and money. In order to get closer to the supplier, understand claims operations, and better service the client, Cohen decided to observe the interactions and resultant attitudes of his suppliers and the clients they serviced in an effort to measure the relationships. His observations revealed the following:

1. Claims operations and its processes were seen as expendable. His desired state was to foster mutual dependency.

2. The business saw procurement as a nuisance which hindered rather than contributed to the business. His desired state was to change the method of supply [re-engineer the value chain] to deliver exceptional service to the end user. 
3. Suppliers were seen as ineffectual, while Operations viewed them as high risk. His desired state was to motivate them through incentives, and work closely with the suppliers to develop sound business partnerships.

4. The customers saw procurement as core. His desired state was to strengthen the relationship by using an alternate value proposition, and technology enabled methodology to deliver the value he proposed.

5. Quality assurance saw procurement's processes as core. His desired state was to strengthen the insurer/vendor relationship to improve profit.

\section{Procurement Past}

The procurement function had undergone a radical transformation in the 3 years prior to the case. Incident Management (IM) services were introduced into the function. Instead of the firm managing the claim from registration, through the assessment stage to the final confirmation of repair stages, the Incident Manager model would take over after claims registration. The strategy relied in large part on pure play price levers which had, over time, become unsuccessful and short-sighted, and delivered little value to the firm's bottom line. Cohen found himself in a predicament where the model was delivering no value, but in the absence of readymade alternatives, the appetite to diverge from the model was sluggish and seemingly non-existent. In John Dewitt's 2014 article, “The Risk of Doing Nothing Haunts Insurance Industry,” David Smith, chief executive officer of Global Futures and Foresight asserted that insurance was "a very complacent industry... and it really wasn't listening [to its clients]" (Dewitt, 2014). From a strategic perspective, a decision had to be made to enable Cohen's desired future state where the complete enterprise value chain was inclusive, enabled, directed, governed, and profitable. Furthermore, if he took the rigidity out of interactions between the firm and their customers, introduced synergies between users [staff and policyholders] and transparency between third party partners [suppliers], he could bring all 3 role-players together on a more interconnected, social, and user-friendly platform such as can be provided by the deployment of a mobile application. For his "to be" process Cohen wanted to elevate the supplier to become a valuable strategic business partner empowered to exercise the freedom to choose the customers he serviced. His proposed solution met the requirement in terms of suitability, feasibility, and acceptability, and provided a fast, centralized, clean source of data while supporting operational activity and strategic objectives over the short, medium, and long term.

\section{Procurement Present}

By reviewing the departmental strategy, Cohen uncovered that the solution he would implement had to position the unit to manage and control all the relevant and contributory inputs. Such positioning would maximize his ability to achieve sustainable results, and ensure that clients developed an active preference for his firm's products and services. This would ensure ABC's desirability and therefore differentiate it from its competitors in the marketplace.

While the customer who received the insurance service was the targeted individual to complete the endof-job customer satisfaction rating survey, in reality, the opportunity existed for suppliers themselves to complete the "ratings card" to ensure only good feedback made its way back to the firm. Not only was the supplier on the back foot in terms of the perception of his ability to provide services quickly and of good quality, but suppliers also had to deal with customers who were already distressed as a result of having suffered an insurable event. 
The inevitable conflicts-of-interest within this process brought three important factors into focus for Cohen: built-in mechanisms for progress measurement while repair job was on-going, actively pursuing client delight at claims registration phase, and better communications management between the firm, the customers, and the suppliers. Within the existing environment no specific technology tools were available besides the standard licensed transactional processing programs that most organizations utilized. In recent months the executive management team of the department began looking at the vanilla version of a local company's software [modeled after a SAP type application] to be customized for procurements purposes. The software would eventually enable and support the day to day operations, provide access to reports, include various workflows and e-tools such as e-catalogues and reverse auctions as part of its vendor selection and evaluation enablement.

Once again, Cohen saw the potential here, and moreover, he perceived an opportunity for his unit to offer a differentiated service product which no other short-term insurer was proposing. He discerned that decisions taken at present would need to stay on par with economic, operational, social, technological, and political trends in the future. The traditional view of insurance claims fulfilment was that the customer was king, and said customer was always right. Outwardly, this was construed as the customer having all decision-making power and being favored over the supplier. Operationally his re-engineered process repositioned the supplier to become as important as the customer, who was equally enabled and an active contributor to the firm's goals. The prevailing operations also exposed the organization to risk related to re-work by alternate suppliers, incursion of costs specific to double administration of the contributors along the claims fulfilment value chain, and resultant quality assurance investigations. The scope of his challenges also included the lack of system resources and data points to accurately measure supplier performance, track the claims lifespan and progression, and lack of claims contributor efficiency which detracted from the organizational goals of growth and profitability.

\section{Procurement Future}

Going forward, Cohen had to ensure claims processes and technologies were proactively aligned to manage leakage, enable a centralized support mechanism for its decentralized claims resolution value chain, install and promote ease of usage functionality, and accommodate for multichannel claims registration capability. Because the contemporary claims handling process was flawed from the outset, client unhappiness with work performed was inevitably noted via the client satisfaction survey which was completed after the repair job was concluded and remained on the supplier’s service history.

Cohen understood that the ideal solution need not include the full suite of supply chain management requirements, but that the solutions capabilities framework had to strike the right balance between form and function. The solution needed to strategically underpin his unit's core activities by impacting methods that supported the business's overall focus and end game. Integrated application platforms would enable the mobilization of support staff in the operations environment which would allow the firm to better serve their customers, and ensure that claims information was always up-to-date. An app would ultimately result in user inputs populating proprietary data assets that could result in the enhancement of its proprietary supplier databases. These databases would then become a future contributor to the firm's world class procurement competence.

In order for him to realize the vision for his own firm, Cohen was forced to ask himself the question: Was ABC Insurance relevant, significantly or otherwise, to any given supplier's organization? If the firm was able to harness, store, and retrieve at a moment's notice its own vast volumes of data via a mobile app solution, his firm would be able to better meet the challenges of catastrophe repair service management via the Operations department in the form of enabled "Assessor" services. By actively managing the assets, contributors, inputs, and outputs along the firm's service value chain, Cohen aimed to achieve significant financial, admin, and strategy gains for the firm. 


\section{The Options}

According to a report on the status of the procurement function by Vision 2020, a continued drive towards cost reduction would no longer be the procurement professionals' most critical function (Ariba, 2011). It went on to report that firm's that were able to ensure the "right processes, tools, skills, relationships, and performance metrics are in place across business lines and functions.” The function would also be less concerned with savings, and more emphasis would be directed toward spend coverage, innovation, collaboration, internal and external stakeholder satisfaction, and competitive advantage. Cohen aimed to use this technological delivery system for supplier/customer relationship management to assist in driving customer/supplier acceptance of future processes and projects, support operations to drive the firm's profitability, and contribute to the firm's top-line growth while positively impacting the bottom-line. IBM’s 2020 scenario report further supported the Vision 2020 report by highlighting 5 key findings insurance industries would be exposed to, based on impending social and technological change (IBM, 2006):

1. Mega trends would force the insurance industry to innovate

2. Old modes of thinking would threaten the insurance industry’s ability to innovate

3. Interlopers would increasingly disrupt traditional insurance operations

4. Industry leaders would require experimentation in operating models, processes, products, and customer relationships

5. Strategic investment in innovation today was critical to future success

The re-engineered process met all the benchmarks to ensure his vision of being accountable, lowering costs, and delivering value now and over the long-term would be realized. It also met the firm's needs in terms of suitability, feasibility, and acceptability. He did not foresee a standalone app as being ideal since he needed a tool that was digitally enabled to assist in the execution of user tasks, and enable maximum performance of his re-engineered processes. More suited to his goals was a corporate app which could help his unit to stay relevant. As evidenced in the World Insurance Report (2016), "Insurance companies must prepare themselves, start leveraging technologies and significantly change how they asses and manage risk. They will also need to streamline processes, build data and analytic capabilities, improve their value proposition and services, and establish strategic alliances.” Cohen found himself pondering the interactivity of the tool, its component design requirements, and the branding requirements he was sure he would need to adhere to in terms of corporate image and brand association. Cohen therefore realized he would need to make provision for such a technology in his budgeting for the new financial year, whereby the depiction in Exhibit 2 reflects Cohen's vision of the re-engineered process a corporate app would enable. This would solidify the roadmap pinpointing the intersection where technology and risk management met.

\section{Option 1: Stay as Is}

With his new-found awareness of internal processes, the firm's strategic goals, and own his re-imagined version of the non-automobile property and casualty business unit, Cohen assessed the cost benefit ratio of not adopting a procurement digital solution. The immediate Rand value cost would be zero as there would be no associated monthly fee, software licensing, or web hosting charges. The further cost, in relation to the company's overall strategy, was the risk of executive managers missing out on an 
opportunity to infuse transparency into daily operations and business interactions inside the firm's functional areas. The constraints of the existing system would force the firm to add extra admin and manual resources thereby clogging up human resource capability, location resources, and would also add extensive load on existing operations processes. This would effectively negate the firm's ability to increase its underwriting margin, minimize claims leakage, or redress the repercussions of the existing data gap. Mobile technology would effectively shift the "Customer/Supplier/Claim" team from "process execution robot" to "insight-driven, intelligence led decision maker."

\section{Effect on the Firm}

In contrast to organizations in the ICT and telecommunications industries, Cohen realized his own organization was at ease to some extent with using technology to report on risk events or notify customers of potential insurable events, but not comfortable enough to use technology to contribute, monitor, and control the facilitation and execution of repairs services. By remaining "as is" claims operations managers would not have access to deeper, more meaningful analytical views of business transactions. Nor would they be able to definitively answer mission critical business questions which fully support the firms overarching strategic and customer service goals. Having produced authentic real-time proprietary claims data, the firm would empower itself to carry out improved risk selection and risk detection activities. In addition, the app had the potential to become a goldmine of information for insurance assessors, as advances in technology had the potential to change the way the firm did business in the areas of mobile/digital assessments and moving picture or 3D touch technology when assessing accident or catastrophe damage.

Also, assessors may need to service many customers over an extended period of time in terms of first aid information, facilitating the enablement of emergency repair services, handling further weather warnings, stopping flowing municipal water on their properties, and enabling assessors to link to contracted security, hotel, and vehicle hire suppliers if required. Cohen reasoned that the app could eventually become vital to future procurement spend direction decisions as an integrated cost and management tool. Facilitator apps could become an important aspect of the firm's customer related goals. Cohen identified prospective deployments such as "what to do lists" for customers in emergency situations, or "frequently asked questions" databanks for suppliers to reference when dealing with particularly difficult on-site repair scenarios. The firm could also utilize facilitator apps to assist suppliers in confirming they had the correct quantities of materials and tools to efficiently service the clients they had on their job cards for the week, remind suppliers of the legislated company documents that needed to be submitted to the firm on an annual basis, or even deploy translation capability between customers and suppliers.

\section{Effect on the Customer}

Customers and their insurable assets could potentially become underserved by not exploiting innovative solutions. By embracing an "Uber like” business model, customers could be empowered to either give consent or to pass over suppliers before service providers were dispatched to private residences, and the firm could proactively manage the anxiety of policyholders [associated with the high crime rate of the country]. Technology could also be used to empower homeowners during emergency situations by providing interactive support in real time to locate and turn off the water to the residence to minimize resultant flooding damage due to pipe bursts. Cohen saw it as critical for the short-term insurance industry to take advantage of IOT opportunities. The "Internet of Things" facilitated communications between devices, people, and things, and was an appealing prospect for Cohen by linking:

1. IT enabled mobile devices, policyholders, and geysers (preventative strategy)

2. IT enabled mobile devices, suppliers, and geysers (remedial strategy) 
3. IT enabled mobile devices, insurers, and geysers (monitoring and control strategy)

4. Effect on the Supplier

Suppliers would potentially lose out on opportunities for transparent business interactions between themselves, the firm, and the customers. The most notable benefit of technology would be the suppliers' ability to respond to and remediate customer discontent on-site in real time almost instantaneously. The supplier would also be excluded from opportunities to collaborate with the firm on the acceptance of customers and the occasion to equally rate the customer.

\section{Option 2: Build}

Cohen had to consider designing the tool in such a way that it would stand up to technological requirements and innovations that may occur in the future. Compatibility, speed, and ever changing user requirements were development aspects he knew the firm would need to keep updated constantly once an app was on-boarded. Cohen considered utilizing a mix of freeware technologies such as Apache web server, and Linux operating systems for backend hosting and processing, while using "SourceClear Open” for the development of the app. That would also allow developers to check open source code projects against a database to ascertain if there were security vulnerabilities, and if so, would steer the developers to available patches for the vulnerabilities.

Mobile web apps offered the ability of running in a mobile browser, and would convey a sense of familiarity to the user as it ran on iOS, Android, and Windows platforms. Standard development would include the use of technologies such as HTML (Hyper-Text Markup Language), CSS (Cascading Style Sheets) and Java. HTML would facilitate the foundations or building blocks of the firm's app, CSS could be used to enhance the esthetic appeal and visual context [including branding conformities] of the app, and Java to enable the apps behaviors and range of capabilities. Native Apps would offer him optimized performance that was faster and guaranteed the best UX (user experience) and UI (user interface) capabilities. Hybrid [part web/part native] apps offered less flexibility in terms of optimization, and their own set of challenges related to the potential plethora of plug-ins that may be required for the app to function as intended.

The app needed a light frontend which would reduce the load on the server, be highly efficient to navigate, and guarantee quick upload speeds and performance. Integrating the lightweight front end with a robust back end, would help with monitoring and control activities, and would allow for more apps to be brought into scope [in the future] for implementation. If he was able to achieve the ideal design right from the outset, he could limit the odds of operations and backend resources becoming overwhelmed by the amount of data they were collecting. This could be achieved by applying JavaScript Object Notation. JSON's lightweight data-interchange format lessened the exemplification of data in graphical format, thus facilitating quick parsing and generating which was perfect for dashboard creation. Besides utilizing Platform-as-a-Service (PaaS) methodologies to tie mobile application development environments to backend infrastructures, Mobile-backend-as-a-Service (MBaaS) middleware could connect the mobile app to the firm's existing infrastructures. The main benefit of MBaaS was that it could connect to existing data without having to relocate or modify the data in any way. It could also extend its capabilities for development re-use and duplication for other mobile application solutions while supporting web based desktop computing applications. 
Even if the required IT assets were already present in the firm, he had to weigh the enterprise cost of time to implementation, the monitoring and control requirements to ensure the digital solution functioned as it should and, most importantly, the firms associated return on investment. Within the organization, he would need to consider the existing digital capability, and if the existing resources were sufficient to support a solution in terms of mobile operating systems, approaches to device management, application management, and user agreements. The firm would not necessarily require specialized skills in coding for all aspects of development and testing as useful tools such as MIT App Inventor did not necessarily require developers to know how to hard code (http://appinventor.mit.edu). Further support from ATFW (Ask The Fantastic Web) queries [i.e., Googling] could also assist developers with debugging their existing code, and freely available mobile device emulators available on the web could be employed to test the functionality of the app throughout the development lifecycle.

In keeping with recommendations by research analysts at Gartner, Cohen wanted testing to be undertaken in-house with employees who would perform real business tasks to get the best result and test data (www.gartner.com). The use of technologies such as JMeter would provide the necessary information regarding the solutions performance, scalability, and functional behavior. Here, Cohen saw an opportunity for the firm to divert some of its primary IT activities from frequent routine maintenance activities which came standard with older or legacy systems, to more IS (Information Systems) and developer type roles. This would give him the scope and agility to streamline the app’s workflows right from the start.

By doing so he would also create the opportunity to uphold and support the firm's business intelligence (BI) initiatives by accommodating for the types of corporate data the technology needed access to, the corporate applications the tool needed to interface with, and the methods it would use to access those platforms. This would allow him to accommodate for the effects of the tool on existing storage, network, and computer resources within the firms present day architectures and data infrastructures. Technologies such as Underscore.js could campaign on the app to either collaborate with a preferred supplier, or to provide information and support should a nationwide insurable event occur. Such campaigns would be created on single page web app template that would not need to interface with the server every time there was an update, thus eliminating drag on server resources.

\section{Option 3: Buy}

Cohen found many Enterprise Mobility Management (EMM) companies who were willing to develop, host, and integrate an app. Some had on-premises support, and some had the ability to assist the firm in developing new, expanding existing, and delivering more mobile app solutions in the future. He knew he had to achieve equilibrium between the total cost of ownership implications-in terms of modifications related to source code - the materiality of various vendor restrictions, and international and domestic legalities surrounding software licensing and copyrighted software solutions.

His primary concern related to these offerings was exposing his firm to vulnerabilities. Exposure was associated with the ownership and modification of the source code. Would the vendor's product be shareware enabled, and would the re-distribution of the vendors technology be a major risk to his business? Should the developers of the code abandon it, what was the vendor's mitigation strategy in terms of “end of life” planning, and more importantly, continuity of his firm's business operations--its obligations, and its way forward? Was the level of access to insider information an external party may come across substantive enough to present real risk in relation to his company's strategies and future expansion plans? Was possible relinquishment of the intellectual property of an app's customized functionality a barrier in the evolution of his business unit and in the end his firm's requirements? The security of transactional information would be a critical deciding factor for Cohen, and the vendor solution would need to comply with required corporate governance, legislature corporate and client data security, and transactional audit capability. Legalities around limitations and variations of the licensing, 
copyrights, and the vendors exclusive rights including lock-in clauses in terms of wholly owned and formerly open-sourced proprietary solutions needed to be considered. In addition to that, the vendor had to ensure that the app would be available on all mobile operating systems with the required functionality intact. He needed all hacking and breaching attempts to be traced back to the source, and assurance that nuanced requirements for most mobile platforms or operating systems had been catered for by vendors when designing their products.

His second major consideration was whether the solution was designed with his customers and target audience firmly in scope. From a customer perspective, he had to be sure that the tool was not only user friendly, but that the firm was not opening itself up to risk by unknowingly granting an external vendor or program unwarranted access to policyholder information in line with the statutes of the POPI (Protection of Personal Information) Act (POPI, 2013). He also had to consider how the vendor would deal with disruption to his business operations as a result of failure of the vendor's product, and what after-sales support the vendor offered, such as patch management and error handling. While there were Application Programming Interface (API) and Software Development Kit's (SDK) that could provide security access controls, the risk existed that by subverting some mobile OS's security protocols, the vendor may have inadvertently succeeded in subverting the devices own security controls and protections.

Furthermore, the product needed to conform to the prescripts of TCF where the firm would not make business decisions that would negatively impact its customers, including POPI in terms of cloud computing for warehousing and storage of certain types of data. Security such as Identity Access Management (IAM) considerations would also have to be taken into account where only authorized employees would have pre-approved access to certain applications, data sets, and operational support technologies and servers. In reverse, Cohen had to consider the implications of wiping suppliers' digital devices used in the performance of insurance related work once they were no longer on the panel, or a customer when they cancelled their policy with the firm. ABC Insurance had also been approached by many companies who operated in the IM space over the preceding 12 months offering their app's in the hopes that ABC would come onboard by either outright purchasing their app, or by bringing their technology onboard in partnership agreements. While many of the demo apps Cohen saw initially did fulfill aspects of what he required, none of them came close to scratching the surface of what the firm needed.

\section{Option 4: Hybrid Option}

In pursuing the above options, he realized he also had a fourth option available to him. By following a mixed approach incorporating both built and bought components, he theorized he could successfully, at the very least, defend his firm's position within its industry. Since the core focus underpinning the stimulus behind the initiative was the customer, Cohen believed that through technology he would in effect be treating all his customers (internally and externally) fairly. The quality of the commitment by the internal stakeholders and the utilization of optimized business processes by newly created business partners in the re-imagined procurement value chain, he believed, would all align to create the perfect storm of client delight, differentiation, and profit which his enthused competitors would find hard to surpass.

\section{The Case for Digital Enablement}

Whether the final decision was to build or to buy, Cohen knew that an enterprise portal was paramount if he was to get his businesses procurement repair information right for the future. With his focused intent of 
on-boarding this digital technology, he would enable the firm to integrate disparate information sources and applications within its operational environment[s], and allow its employees and suppliers to do their jobs in one single location, within a unifying framework. He realized the firm had an opportunity to bring to the market a differentiated service where the energy store (charged battery life) of devices could become a part of his supplier engagement strategy. Software-as-a-Service (SaaS) technology or "Cloud" services allow users the ability to access internet based services over wireless networks. The frequency of users accessing this type of service, and the resultant network communications between the cloud and the mobile device, rapidly depletes the device's battery power reserve which he could monitor using application performance monitoring (APM) software that would allow him to measure the apps resource utilization and network latency to ensure an acceptable user experience. By utilizing the right mix of technologies, he knew that he could lessen the energy load on user's mobile devices by using service component migration between the mobile device [as part of the cloud], and the infrastructure-based cloud, as a means to conserve power on the mobile device battery, which was especially relevant because of electricity supply problems in the country.

As the service providers carried out on-site repairs, they most likely would have no access to municipal power sources. Equally, the same technology benefits could be extended to customers who may be experiencing power outages as a result of a weather related phenomenon. Without a mobile app to facilitate a platform for shared insight, the supplier could not make the necessary modifications to improve the customers' experience or improve on repair work in progress if he/she was unaware that the customer was unhappy. The firm would also be able to ensure suppliers in particular provinces were aware of changes in the environment such as: water restrictions imposed by municipalities, the local preservation restrictions on noise, and earth moving or groundwater run-off implications to wildlife or designated wetlands in close proximity. The supplier would then become a valuable business partner to the firm by capitalizing on opportunities to curtail the final cost of the repair which would in due course write procurement savings straight to the bottom line.

\section{References}

Apartheid. (2016). In Wikipedia. Retrieved from https://en.wikipedia.org/wiki/Apartheid

Ariba. Vision 2020: The future of procurement. (2011, January). Retrieved from https://www.ariba.com/resources/library/library-pages/vision-2020-the-future-of-procurement

Black Diamonds. (2016). In Wikipedia. Retrieved from https://en.wikipedia.org/wiki/Black_Diamonds_(racial_term)

Dewitt, J. (2014). The Risk of Doing Nothing Haunts Insurance Industry. Retrieved from https://www.thefreelibrary.com/The+Risk+of+Doing+Nothing+Haunts+Insurance+Industry.$\underline{\mathrm{a} 0356685539}$

FSB: The Financial Services Board: Short-term insurance. (n.d.). Retrieved from https://www.fsb.co.za/feedback/Documents/Short\%20Term\%20Insurance.pdf

Gillwald, A., Moyo, M., \& Stork, C. (2012). Understanding what is happening in ICT in South Africa: A supply-and demand-side analysis of the ICT sector. Evidence for ICT policy action. Policy Paper, 7. Retrieved from https://www.researchictafrica.net/publications/Evidence_for_ICT_Policy_Action/Policy_Paper_7__Understanding_what_is_happening_in_ICT_in_South_Africa.pdf 
IBM. (2006). Insurance 2020. Retrieved from https://www-935.ibm.com/services/us/gbs/bus/pdf/g5106291-01-insurance-2020.pdf

Insurance as a grudge purchase. (2008). South Africa's Insurance Times and Investments. 21(1). Retrieved from http://www.insurance-times.net/article/insurance-grudge-purchase

KPMG. 2016 South African Insurance Survey. (n.d.). Retrieved from https://home.kpmg.com/za/en/home/campaigns/2016/07/2016-south-african-insurance-survey.html

Opportunity for insurers in Africa - SA insurance body. (2015). Retrieved from https://www.fin24.com/Companies/Financial-Services/Opportunity-for-insurers-in-Africa-SAinsurance-body-20150730

POPI: Protection of personal information act. (2013). Retrieved from https://www.saica.co.za/Technical/LegalandGovernance/Legislation/ProtectionofPersonalInformati onAct/tabid/3335/language/en-ZA/Default.aspx

South African Audience Research Foundation (1993). Living standards measure. Retrieved from http://www.saarf.co.za/lsm/lsms.asp

South African Department of Trade and Industry. (n.d.). Broad-based black economic empowerment. Retrieved from http://www.dti.gov.za/economic_empowerment/bee.jsp

Statistics South Africa. (2012). South African statistics, 2012. Retrieved from http://www.statssa.gov.za/publications/SAStatistics/SAStatistics2012.pdf

UN Human Development Report. (2015). Work for human development. Retrieved from http://hdr.undp.org/sites/default/files/2015_human_development_report.pdf

World Insurance Report. (2016). 2016 World insurance report. Retrieved from http://riskinfo.com.au/news/files/2016/03/WIR_2016.pdf 


\section{Biographies}

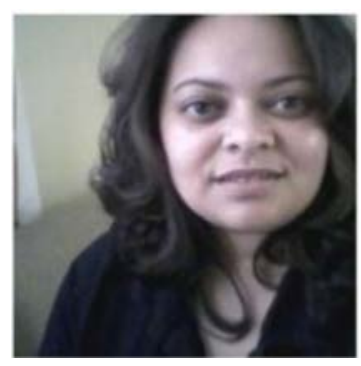

Kim Cupido has been working in the Procurement field for 12 years, and has worked in the insurance industry for almost 8 years. She has a Bachelor of Commerce degree with her fist major in Information Systems, and her second in Industrial Psychology. Kim has just completed her Honors degree (B.Comm)(Hons) in Information Systems and is looking forward to pursuing a change in career specializing in Business Intelligence and Data Analytics which holds particular interest for her.

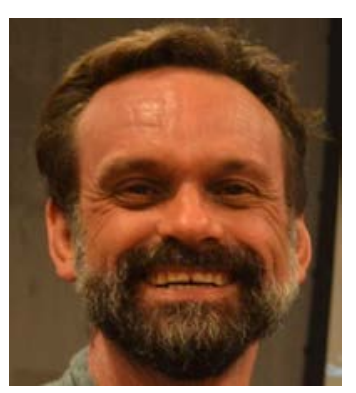

Jean-Paul Van Belle is a professor in the Department of Information Systems at the University of Cape Town and Director of the Centre for IT and National Development. His research areas are the adoption and use of emerging technologies in developing world contexts including mobile, cloud computing, open and big data. His passions are ICT4D - with a focus on emerging technologies as well as data for development (D4D) in an SDG context - and adoption of ICTs by small organizations. He has over 170 peer-reviewed publications including 25 chapters in books and about 40 refereed journal articles. He has been invited to give a number of keynote presentations at international conferences and holds an honorary professorship at Amity University. He currently supervises almost 20 Masters and PhD students and has graduated many more. Jean-Paul has active collaborations with researchers in India, UK, Ethiopia, Kenya and Mauritius. Research interests: ICT for development (ICT4D); emerging technologies; data revolution and SDGs; ICT use by small organisations. 


\section{Exhibit 1: Critical Areas for Re-Engineering}

\begin{tabular}{|c|c|}
\hline Areas to Re-engineer & Rationalization \\
\hline $\begin{array}{l}\text { Achieving supplier focused strategic } \\
\text { alignment facilitating critical mass for } \\
\text { procurement benefit }\end{array}$ & $\begin{array}{l}\text { Which supplier to choose as business partners is mission } \\
\text { critical to supplement the absence of system outputs of line } \\
\text { item costing detail and usage figures which formulate the } \\
\text { basic information on which to make strategic procurement } \\
\text { decisions. }\end{array}$ \\
\hline $\begin{array}{l}\text { Alignment of customer/supplier } \\
\text { engagement channels to serve target } \\
\text { segments: } \\
\text { i) Understanding what and how the } \\
\text { customer wants to buy } \\
\text { ii) Re-engineer distribution network } \\
\text { match customer need } \\
\text { iii) Eliminate low-value and no-value } \\
\text { processes }\end{array}$ & $\begin{array}{l}\text { Claims servicing cycle can only be improved if Procurement } \\
\text { can control the method of choice of supplier [by the } \\
\text { customer], and the choice of customers to service [by the } \\
\text { supplier]. Only once this is in place the firm can develop } \\
\text { trends on client purchases, enable client delight through } \\
\text { appointing the most suitable (skills) and nearest supplier } \\
\text { (geographically + availability) who can quickly respond to } \\
\text { clients' needs. }\end{array}$ \\
\hline $\begin{array}{l}\text { Focused enablement of high levels of } \\
\text { supplier service, supplier repair quality, } \\
\text { and customer satisfaction. }\end{array}$ & $\begin{array}{l}\text { Swing balance of power from Claims Operations to } \\
\text { Procurement. Earnest development of meaningful supplier } \\
\text { service measurement mechanisms. Supplier reward cost will } \\
\text { be offset by optimization of bottom-line procurement process } \\
\text { payoffs. }\end{array}$ \\
\hline Collecting the right data & $\begin{array}{l}\text { Measure the right things - measure things right. This } \\
\text { philosophy will only be apparent once we can measure } \\
\text { precisely what has occurred through being able to conduct } \\
\text { full data mining on our systems in terms of customer records } \\
\text { and specific spend details. }\end{array}$ \\
\hline
\end{tabular}

Source: Strategic Implementation Workbook, ABC Insurance, September 2012 


\section{Exhibit 2: "To Be" Mobile Solution}

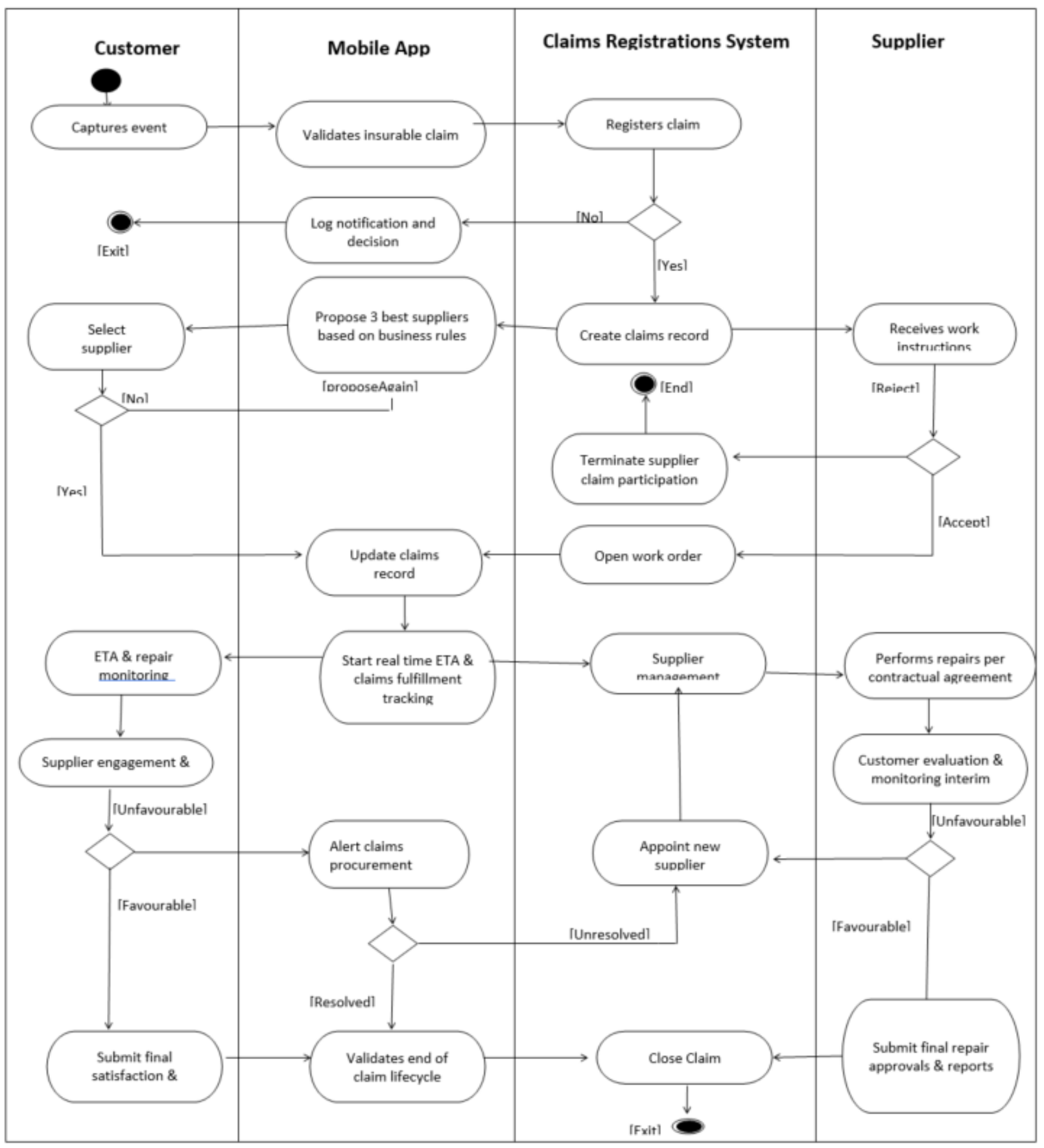

Source: Property \& Casualty Commodity Strategy, Team Presentation (February 2014) 


\section{Exhibit 3: Procurement Support of Company Strategy}

\begin{tabular}{|l|l|l|}
\hline Identifier & Target & Procurement Involvement \\
\hline 1 & $\begin{array}{l}\text { Grow Market } \\
\text { Share }\end{array}$ & $\begin{array}{l}\text { Direct responsibility to potential for growth of market share by effective } \\
\text { on the job monitoring of repairs, and efficient management of suppliers }\end{array}$ \\
\hline 3 & $\begin{array}{l}\text { Manage } \\
\text { Underwriting Risk }\end{array}$ & $\begin{array}{l}\text { Non-management of suppliers contributes to risk by not ensuring } \\
\text { adequately skilled suppliers are available in the required locations }\end{array}$ \\
\hline 4 & $\begin{array}{l}\text { Operational } \\
\text { Efficiency }\end{array}$ & $\begin{array}{l}\text { Enables efficiency by eliminating detractors to repair process thereby } \\
\text { reducing lag and shortening turnaround time to satisfactory completion } \\
\text { of repairs }\end{array}$ \\
\hline Flow & $\begin{array}{l}\text { Facilitates an increase of revenue by eliminating re-work, reappointment } \\
\text { cost, and negating risk of policy cancellations. }\end{array}$ \\
\hline
\end{tabular}

Source: Property \& Casualty Commodity Strategy, Team Presentation (February 2014) 
Exhibit 4: Inefficiency in the Communications Process

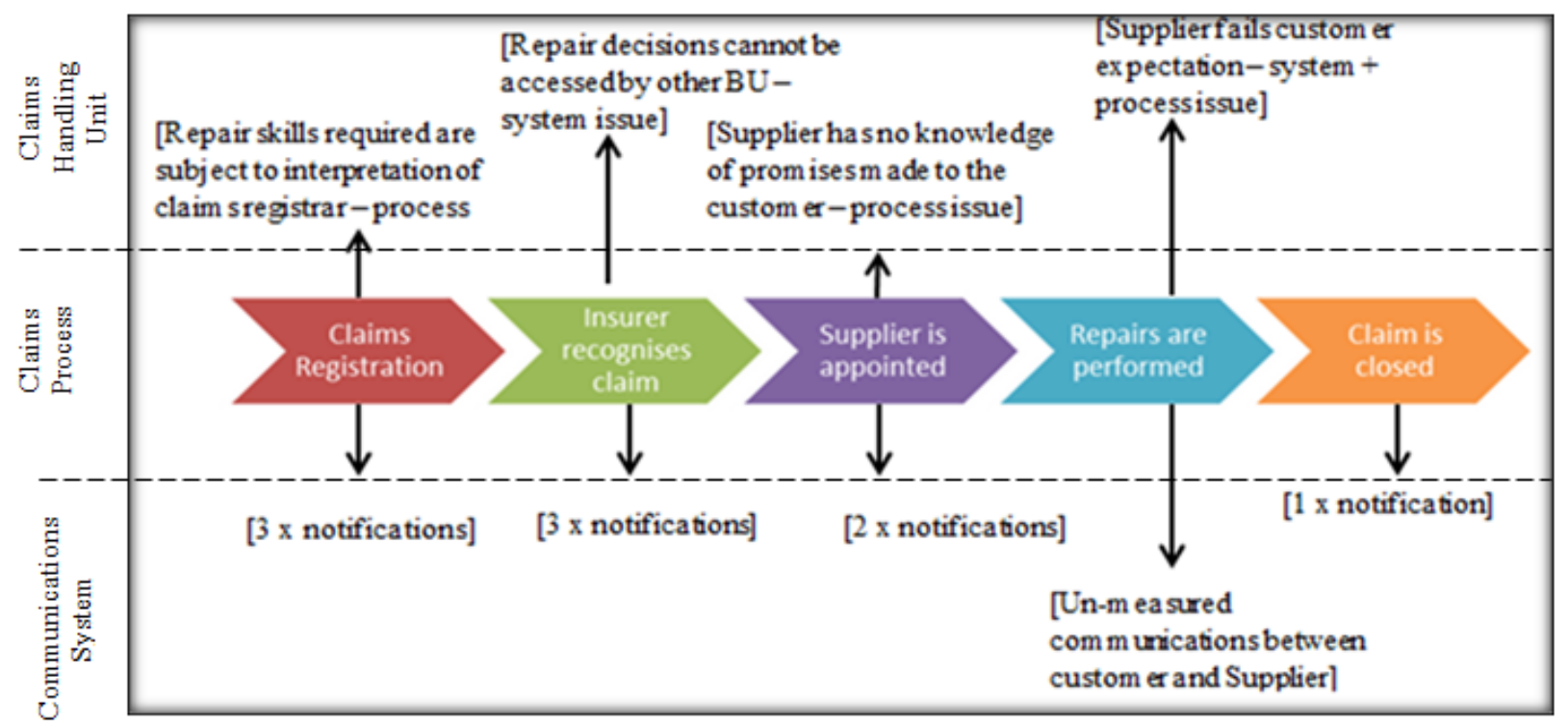

Source: Correlated claims handling process and inefficient communications (modified by case writer) 


\section{Exhibit 5: Procurement Sourcing Process}

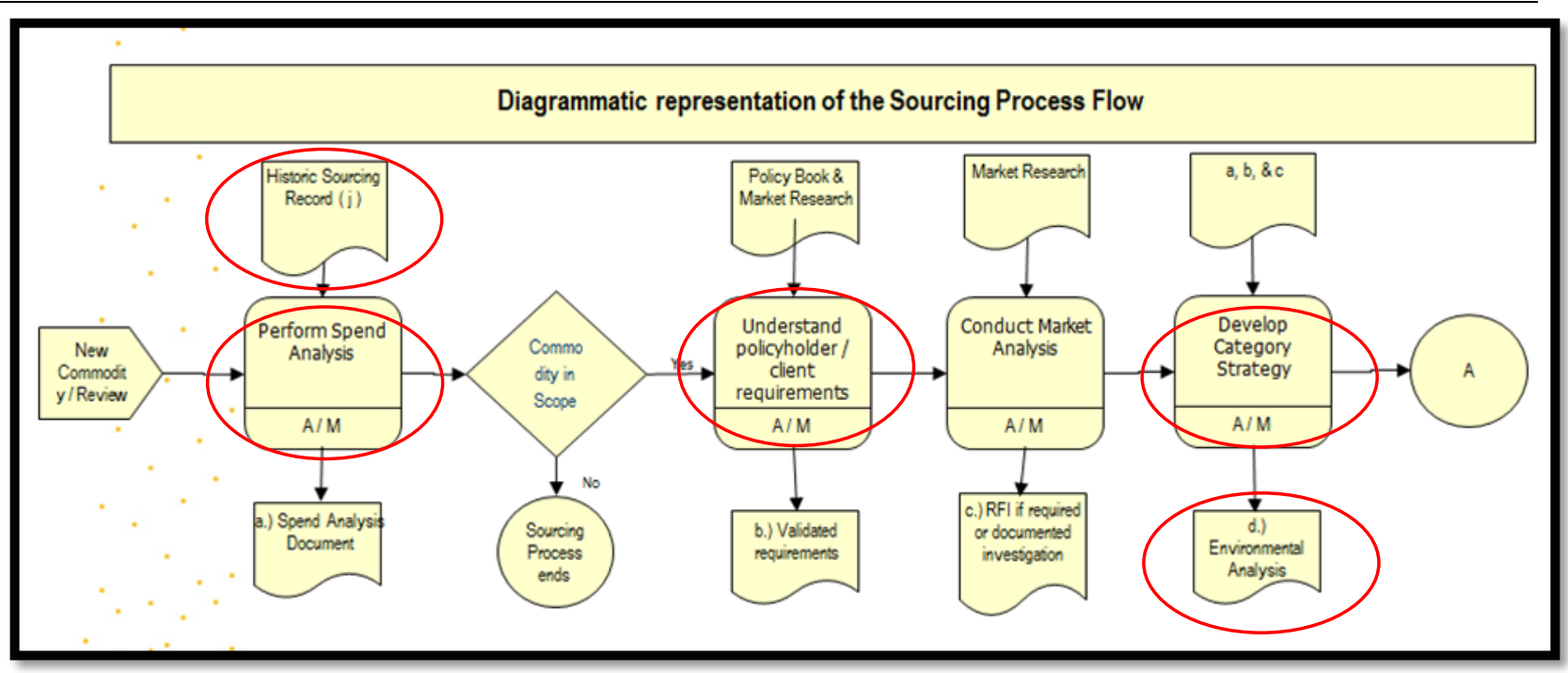

Source: Property \& Casualty Procurement Process Segmentation, November 2015 


\section{Exhibit 6: Options: Advantages and Disadvantages of Each}

\begin{tabular}{|c|c|c|c|}
\hline \hline Options & Advantages & Disadvantages & Missed Opportunities \\
\hline As is & Cost Containment & $\begin{array}{c}\text { Stagnation of } \\
\text { customers/suppliers/employees } \\
\text { Outdated architectures \& technologies } \\
\text { Inefficient processes } \\
\text { Ineffective policies }\end{array}$ & $\begin{array}{c}\text { Innovation } \\
\text { Agility }\end{array}$ \\
\hline Build & $\begin{array}{c}\text { Customized Solutions } \\
\text { Optimization of people, } \\
\text { processes, systems }\end{array}$ & $\begin{array}{c}\text { Extended Time Period } \\
\text { Cost of Acquisition }\end{array}$ & Revitalization \\
\hline Buy & $\begin{array}{c}\text { Cost } \\
\text { Cendor management }\end{array}$ & $\begin{array}{c}\text { Vestrictive contract clauses } \\
\text { Potential for active software escrow } \\
\text { complexities }\end{array}$ & Ownership \\
\hline
\end{tabular}

Source: Modified by case writer to quantify the value/risk of the options 